\title{
Residents protest illegal interview questions
}

\author{
Cite as: CMAJ 2017 January 16;189:E88-9. doi: 10.1503/cmaj.109-5365
}

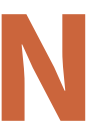
early a third of Quebec medical residents, mostly women, reported being illegally questioned about their family plans during job interviews, according to the Fédération des médecins résidents du Québec (FMRQ).

A survey of 772 doctors in their last year of residency or first year of practice showed that $31.5 \%$ of those who interviewed for jobs reported being asked if they had children or were intending to have children. Women were the main target of these questions, which are forbidden under both Quebec and Canadian charters of rights. Only $14 \%$ of men reported being asked if they planned to have children versus $30 \%$ of women.

The results are shocking and unacceptable, say FMRQ President Dr. Christopher Lemieux. "It's a huge number and we didn't think it would be that much," he says. Not only are such questions illegal, "it has nothing to do with the job."

The potential for discrimination is high. Health organizations must meet increasing patient demands on tight budgets, as more young doctors vie for a limited number of positions, Lemieux adds. Of the survey respondents who admitted they had or wanted children, " $50 \%$ thought it negatively impacted their interview," he says.

FMRQ is urging the province to issue explicit directions to health organizations about the types of questions that are acceptable and unacceptable to ask in hiring interviews. Although questions about family status, pregnancy and marital status are already illegal, it's clear that interviewers need a reminder, says federation vice-president Dr. Valérie Martel. "It's not specific to one or some regions; it's everywhere."

Because interviews are usually conducted by senior physicians, FMRQ is also asking medical associations to educate their members about the problem. Martel argues that many interviewers already know they're skirting the law because they often ask questions about children in roundabout ways. Often it comes up informally, at the beginning or end of the interview, she says. "They make it feel like chit-chat to get to know each other."

Caught on the spot, most residents will answer truthfully, even when they're told they don't have to, Martell adds. Partly that's because there's no right answer to the question. "If I say no, I don't have kids, it may mean I'll have them soon, and if I say yes, I have four kids, they may think I won't be as useful as someone more available."

Lemieux notes that even refusing to answer is "basically saying you want children." And there's little option for recourse beyond suing a potential employer, he says. "Even if you win, it doesn't give you the job."

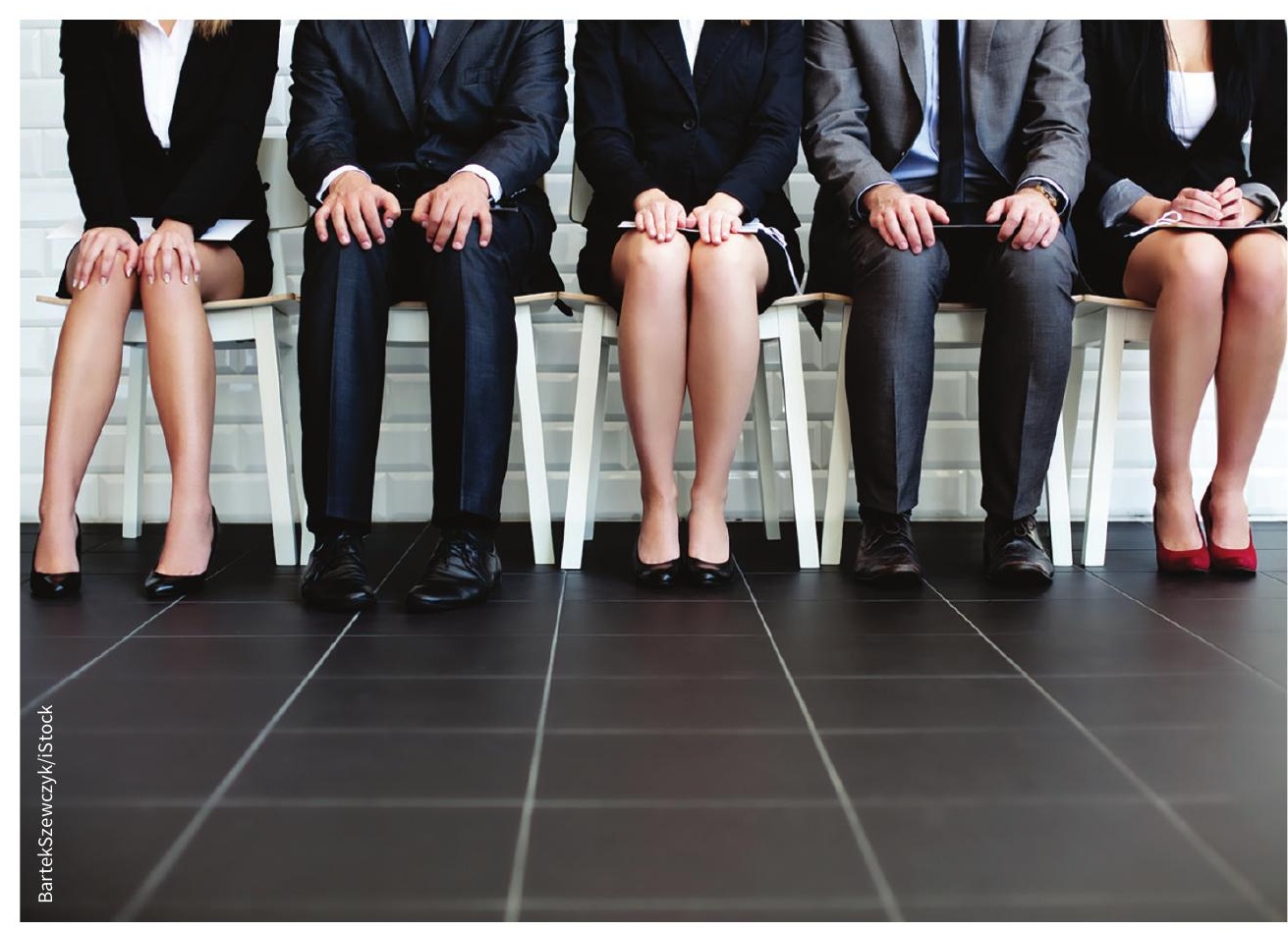

Half of residents who admitted they have or want kids fear it hurt their chance of landing a job.
That's why it's important to address discrimination from the top down "to make sure everyone gets the message this is not acceptable," he says.

Asked whether Quebec will issue an explicit directive to health organizations, the ministry of health stated that the law already prohibits discrimination. "Every person must conform to the law, including health organizations," says spokesperson Marie-Claude Lacasse.

Lacasse didn't answer whether the ministry should provide additional education in cases where institutions are contravening the law.

Lemieux says the ministry's response is "disappointing," particularly given the government's role in increasing pressure on physicians and institutions to do more with fewer resources and no back up. For example, understaffed teams may be less willing to hire someone 
planning to have children if the government won't pay for additional staff to cover maternity leave. New family medicine quotas that require physicians to take on 500 patients in their first year also add to the pressure, Lemieux says. "If you go on leave, then your region won't do well." The fact that men as well as women are questioned about children suggests a bigger problem of unrealistic expectations in the profession, he says.
"There's a lot of pressure to work and work and work and it contributes to the risk of burnout."

Martel notes that residents elsewhere in Canada may face the same or worse discrimination. Residency programs outside Quebec tend to ask "more personal questions, like: is your boyfriend going to come to the same city?" she explains. "They shouldn't ask if it's your first choice, for example, but some do ask if you've applied to anywhere else." It stands to reason that similar questions may be asked during hiring, she says.

Now that the survey has revealed the scope of the problem, "I would hope this matter would be fixed before next year's interviews," Martel says. "It's civil rights; once we know, we don't have a choice but to act."

Lauren Vogel, CMAJ 